\title{
Corrigendum: Curcumin $\beta$-D-Glucuronide Modulates an Autoimmune Model of Multiple Sclerosis with Altered Gut Microbiota in the Ileum and Feces
}

\author{
Sundar Khadka ${ }^{1 \dagger}$, Seiichi Omura ${ }^{1 \dagger}$, Fumitaka Sato ${ }^{1 \dagger}$, Kazuto Nishio ${ }^{2}$, Hideaki Kakeya ${ }^{3}$ \\ and lkuo Tsunoda ${ }^{1 *}$ \\ ${ }^{1}$ Department of Microbiology, Kindai University Faculty of Medicine, Osaka, Japan, ${ }^{2}$ Department of Genome Biology, Kindai \\ University Faculty of Medicine, Osaka, Japan, ${ }^{3}$ Graduate School of Pharmaceutical Sciences, Kyoto University, Kyoto, Japan
}

\section{OPEN ACCESS}

Approved by:

Frontiers Editorial Office,

Frontiers Media SA, Switzerland

*Correspondence:

Ikuo Tsunoda

itsunoda@med.kindai.ac.jp

${ }^{\text {t}}$ These authors have contributed

equally to this work

Specialty section:

This article was submitted to

Microbes and Innate Immunity,

a section of the journal

Frontiers in Cellular and

Infection Microbiology

Received: 15 January 2022

Accepted: 01 February 2022

Published: 01 March 2022

Citation:

Khadka S, Omura S, Sato F,

Nishio K, Kakeya $\mathrm{H}$ and Tsunoda I

(2022) Corrigendum: Curcumin

$\beta$-D-Glucuronide Modulates an

Autoimmune Model of Multiple

Sclerosis with Altered Gut Microbiota

in the lleum and Feces.

Front. Cell. Infect. Microbiol. 12:855411.

do: 10.3389/fcimb.2022.855411
Keywords: bioinformatics, animal model, pattern matching, PICRUSt analysis, bacterial taxonomy, Alpha diversity, confidence interval, histology

\section{A Corrigendum on:}

Curcumin $\beta$-D-Glucuronide Modulates an Autoimmune Model of Multiple Sclerosis with Altered Gut Microbiota in the Ileum and Feces

By Khadka S, Omura S, Sato F, Nishio K, Kakeya H and Tsunoda I (2021). Front. Cell. Infect. Microbiol. 11:772962. doi: 10.3389/fcimb.2021.772962

\section{Error in Figure/Table}

In the published article, there was a mistake in the PDF article as published. Figure $\mathbf{5}$ with its legend is missing from the PDF article, although the HTML article has included Figure 5. The missing Figure 5 with its legend appears below.

The authors apologize for this error and state that this does not change the scientific conclusions of the article in any way.

Publisher's Note: All claims expressed in this article are solely those of the authors and do not necessarily represent those of their affiliated organizations, or those of the publisher, the editors and the reviewers. Any product that may be evaluated in this article, or claim that may be made by its manufacturer, is not guaranteed or endorsed by the publisher.

Copyright $\odot 2022$ Khadka, Omura, Sato, Nishio, Kakeya and Tsunoda. This is an open-access article distributed under the terms of the Creative Commons Attribution License (CC BY). The use, distribution or reproduction in other forums is permitted, provided the original author(s) and the copyright owner(s) are credited and that the original publication in this journal is cited, in accordance with accepted academic practice. No use, distribution or reproduction is permitted which does not comply with these terms. 
A

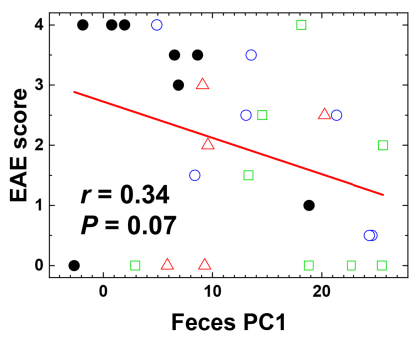

D

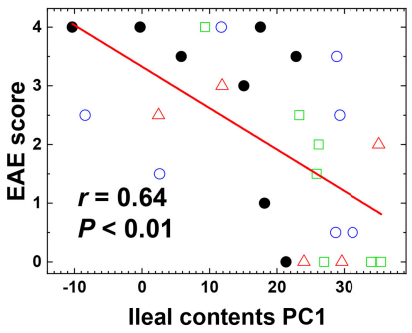

G

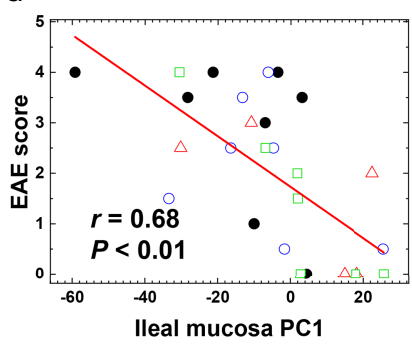

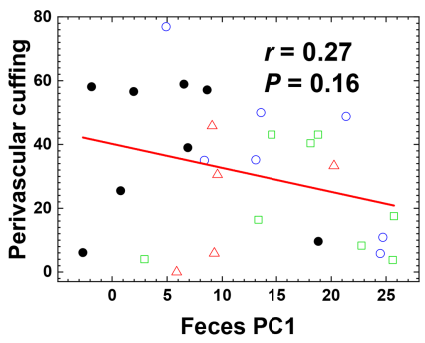

E
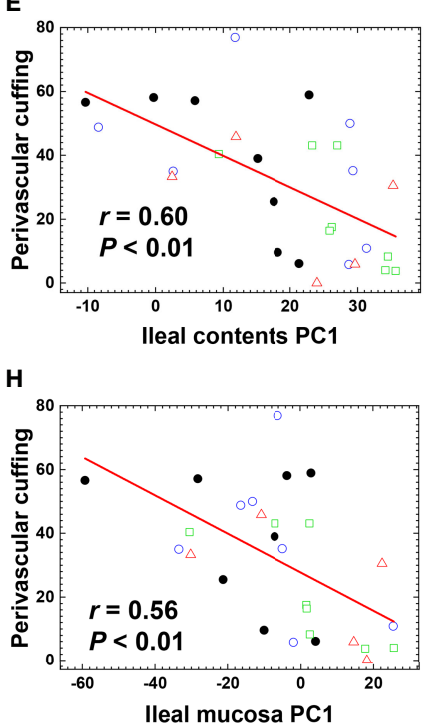

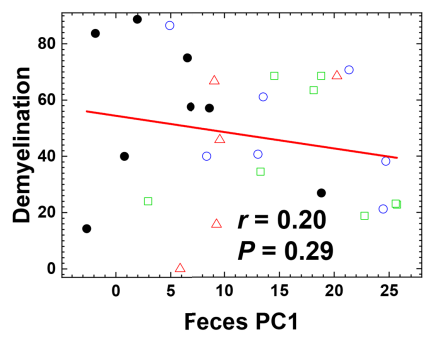

$\mathbf{F}$
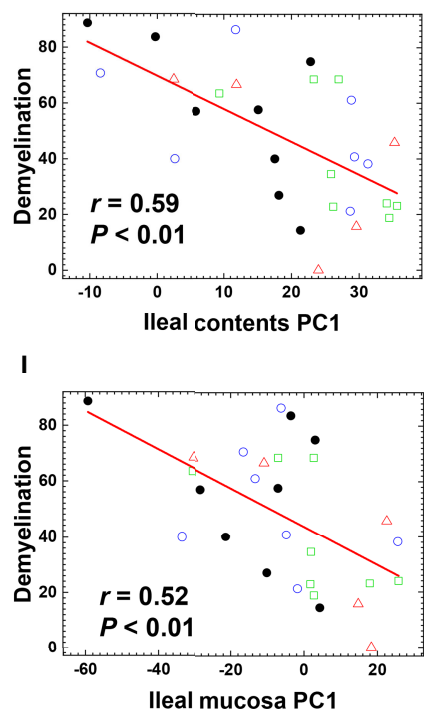

๑: Control; $\bigcirc$ : Induction; $\triangle$ : Latent; $\square$ : Whole

FIGURE 5 | Pattern matching of the microbial PC1 values with the clinical and pathological scores of EAE at the three anatomical sites: feces, ileal contents, and the ileal mucosa. (A-I) We harvested samples from the three CMG-treated (Induction, blue circle; Latent, red triangle; and Whole, green square) and control groups (Control, black circle). The microbial PC1 values of ileal contents and the ileal mucosa, but not feces, significantly correlated with the EAE scores (A, D, G), perivascular cuffing (i.e., inflammation) scores (B, E, H), and demyelination scores (C, $\mathbf{F}, \mathbf{I})(P<0.01)$. 